\title{
O financiamento das empresas inovadoras: alternativas para discussão
}

\author{
Luiz Martins de Melo*
}

RESUMO - O investimento em inovação depende de condições institucionais mais amplas do que aquelas relacionadas diretamente ao poder decisório das empresas. Em especial as políticas, monetária fiscal e cambial, afetam decisivamente as expectativas dos empresários inovadores. Em um ambiente macroeconômico hostil essas expectativas vão direcionar os investimentos para atividades menos arriscadas e inseguras do que a inovação na tomada de decisão de investir das empresas com relação à valorização dos sues ativos.

Palavras-chave: Sistema nacional de inovação. Sistema financeiro. Financiamento. Inovação.

\section{INTRODUÇÃO}

Os empresários tomam suas decisões de investimento tendo como base as expectativas com relação ao comportamento da demanda futura. As decisões de investimento em inovação são uma parte da estratégia de investimento global das empresas.

Dessa maneira eles são afetados, positiva ou negativamente, pelas políticas implícitas e explícitas de apoio ao investimento produtivo e à inovação. Para que se crie um ambiente favorável ao investimento em inovação é necessário que exista uma compatibilidade entre as políticas monetária, fiscal e cambial, as políticas implícitas, e a política de inovação (explícita).

A política monetária através da taxa de juros influencia o preço dos ativos, tangíveis e intangíveis, que serão formados através do investimento das empresas. Influencia também a taxa de câmbio tornando mais barata ou mais cara a compra e aquisição de máquinas e equipamentos, bem como a compra e licenciamento de tecnologia no exterior.

A política monetária conduzida pelo Banco Central também influencia a expectativa com relação ao comportamento futuro da demanda pela regulamentação do setor bancário e do crédito. A manutenção de uma taxa de juros básica elevada por muito tempo também acarreta uma preferência pela aplicação financeira em títulos públicos de menor risco que os

\footnotetext{
* Doutor em Economia da Indústria e da Tecnologia pela Universidade Federal do Rio de Janeiro. É professor adjunto do Instituto de Economia da Universidade Federal do Rio de Janeiro. Endereço eletrônico: luizmelo@fujb.ufrj.br.
} 
privados, operações de arbitragem entre os ganhos financeiros internos e externos, elevação da dívida pública e restrição ao gasto fiscal.

A restrição ao gasto fiscal impede que o governo defina uma política de compras do setor público, que é um dos instrumentos mais eficaz de apoio à inovação.

Todas as considerações feitas indicam que o ambiente institucional no Brasil para o investimento em inovação é bastante hostil. É muito fraca a coordenação e compatibilidade entre as políticas implícitas e explícitas de apoio à inovação.

Nas partes seguintes do artigo será analisado o financiamento do investimento em inovação comparte da estratégia global de investimento das empresas.

\subsection{AS EMPRESAS COMO O CENTRO DE SISTEMA DE INOVAÇÃO}

As empresas são o centro do sistema de inovação. Não há mais dúvida quanto a isso, nem do ponto de vista teórico ${ }^{1}$, nem tampouco do ponto de vista empírico ${ }^{2}$. A própria OMC reconhece este fato, ao admitir os aportes financeiros, entre os quais os subsídios financeiros a pesquisas vinculadas a objetivos produtivos, comerciais e de lucro. Apenas impõe determinados limites ${ }^{3}$.

Para que a firma realize os seus investimentos, ela tem que escolher a sua estrutura de financiamento, isto é, a melhor combinação das fontes de recursos que igualem as condições de prazo, risco e retorno do seu investimento. Um dos problemas mais importantes da escolha da estrutura de financiamento diz respeito ao custo de cada uma das fontes de financiamento e o impacto destas na determinação da taxa de desconto, o que influencia na seleção do programa de investimentos da empresa.

É importante notar que uma empresa sempre recorre a fontes distintas para financiar seus programas de investimento. Essas fontes podem ser classificadas da seguinte maneira:

- Lucros retidos

- Emissão de ações

- Emissão de títulos financeiros

\footnotetext{
${ }^{1}$ OECD (1992) e OECD (1996).

${ }^{2}$ NSF (1998) e NSF (2002).

${ }^{3} \mathrm{O}$ aporte financeiro para as atividades de inovação nas firmas ou por firmas e instituições de pesquisa é limitado em 75\% dos custos totais da P\&D industrial, ou 50\% dos custos de atividades de desenvolvimento experimental (pré-competitivo). Estes gastos incluem pessoal, equipamentos, construções utilizadas exclusivamente para atividades de pesquisa, materiais, insumos e consultoria, incluindo conhecimentos técnicos, patentes etc.
} 
- Empréstimos bancários

Porém, pode ser enganoso falar, de um modo geral, de firmas. Ainda mais quando se trata do financiamento do investimento em inovação. Dessa forma, pode-se simplificadamente, classificar as firmas inovadoras em dois tipos: aquelas estabelecidas e as firmas emergentes de base tecnológica (FEBTs).

Investimento em inovação implica assumir uma incerteza maior do que em investimentos ordinários. Isso vale tanto para a incerteza de mercado quanto para a incerteza técnica. Em adição a isso, os processos de aprendizado relativos a novos produtos e processos são mais lentos e as condições de segurança mais difíceis do que para os produtos maduros. Se as instituições financeiras são avessas ao risco, incerteza e compartilhamento do risco podem ser obstáculos para o financiamento das firmas. Mas um nível aceitável de conhecimento sobre as atividades das firmas pode reduzir, ainda que não eliminar, os problemas de incerteza, facilitando o financiamento. Uma maneira de conseguir esse conhecimento, ganhando mais confiança, é pela realização de repetidos contratos entre credores e devedores. A acumulação de conhecimento através do relacionamento interativo entre firmas e instituições financeiras é um primeiro modo de reduzir as restrições de informação e conhecimento entre as partes.

O quadro apresentado a seguir pode esclarecer melhor as diferenças entre as empresas estabelecidas e as FEBTs.

\begin{tabular}{|c|c|c|c|c|c|}
\hline \multirow[t]{3}{*}{ Fontes de recursos } & \multicolumn{5}{|c|}{ Estágio de desenvolvimento da empresa } \\
\hline & \multirow{2}{*}{$\begin{array}{c}\text { Concepção/ } \\
\text { Criação }\end{array}$} & \multirow{2}{*}{ Start up } & \multirow{2}{*}{$\begin{array}{l}\text { Estágio } \\
\text { inicial }\end{array}$} & \multirow{2}{*}{$\begin{array}{c}\text { Crescimento } \\
\text { Expansão }\end{array}$} & \multirow{2}{*}{ Maturidade } \\
\hline & & & & & \\
\hline Lucros acumulados & & & & $\mathrm{x}$ & $\mathrm{x}$ \\
\hline Governo (doações) & $\mathrm{x}$ & $\mathrm{x}$ & $\mathrm{x}$ & $\mathrm{x}$ & $\mathrm{x}$ \\
\hline Recursos Próprios & $\mathrm{x}$ & $\mathrm{x}$ & & & \\
\hline Sócios - Business angels & $\mathrm{x}$ & $\mathrm{x}$ & & & \\
\hline Sócios - Capital de risco & & $\mathrm{x}$ & $\mathrm{x}$ & $\mathrm{x}$ & \\
\hline Sócios - Private equity & & & & $\mathrm{x}$ & $\mathrm{x}$ \\
\hline Sócios - Emissões públicas & & & & & $\mathrm{x}$ \\
\hline Financiamentos bancários & & & $\mathrm{x}$ & $\mathrm{x}$ & $\mathrm{x}$ \\
\hline
\end{tabular}

\section{O FINANCIAMENTO PARA AS FIRMAS INOVADORAS ESTABELECIDAS}

O aprendizado interativo é o mais apropriado para firmas estabelecidas. $O$ financiamento via crédito, com o estabelecimento de garantias formais, é adequado e encontra respaldo, tanto pelo lado dos ativos das firmas, quanto pela sua estrutura do capital. Dada 
uma taxa de juros e prazos de pagamento compatíveis com a natureza da inovação para a qual se busca financiamento, as empresas não terão problemas em captar recursos no mercado financeiro, nem nas instituições privadas, nem nas públicas. O problema é mais de uma macroeconomia do que da ausência de mecanismos financeiros.

As firmas inovadoras estabelecidas podem ter acesso às quatro fontes de financiamento descritas anteriormente. Elas não terão problemas em utilizar os lucros retidos, pois já possuem uma base de mercado para isso. Já são conhecidas e reconhecidas por seus clientes e fornecedores. Possuem relações estáveis com o sistema financeiro. Têm condições de oferecer garantias para os empréstimos bancários. Também não terão muitos percalços para emitir títulos (debêntures conversíveis ou não). E, se forem de capital aberto, poderão emitir ações para aumento de capital, quando necessário.

O problema principal que as firmas estabelecidas enfrentam, para entrar em um programa mais intensivo de inovação, está relacionado ao elevadíssimo custo de capital e à escassez, no Brasil, de fontes de recurso de longo prazo. É razoável supor que, no caso destas firmas, o instrumento para aporte financeiro mais adequado seja a equalização das taxas de juros. Elas podem fornecer as garantias necessárias e preencher todos os requisitos técnicos, financeiros e contábeis para a obtenção do empréstimo. O que falta é o estímulo da redução do custo financeiro do investimento em um ativo com as características da inovação: alto risco, longo prazo e custo elevado.

Estas características das firmas estabelecidas fizeram com que a equalização da taxa de juros fosse inteiramente incorporada pela atuação da Finep, conferindo uma maior atratividade em relação ao custo dos empréstimos do BNDES. Em 2004, a Finep realizou um total de 41 operações de crédito, das quais 30 utilizaram a equalização (dos cerca de $R$ \$ 328 milhões financiados no total, $\mathrm{R} \$ 301$ milhões foram equalizados). $\mathrm{O}$ valor médio do financiamento chegou a $R \$ 8$ milhões nas operações normais e a $R \$ 10$ milhões nas equalizadas, o que parece indicar uma maior intensidade tecnológica destas últimas.

\section{O FINANCIAMENTO PARA AS FIRMAS EMERGENTES DE BASE TECNOLÓGICA (FEBTS)}

Para as FEBTs pode-se afirmar que o problema é inverso. Elas não têm acesso normal a nenhuma das quatro fontes de financiamento. Lucros retidos são escassos ou inexistentes. É provável que não tenham, até mesmo, geração de caixa suficiente para bancar, na totalidade, as suas atividades correntes. Não possuem uma base sólida de mercado. O seu 
reconhecimento pelos clientes é frágil. Não possuem relações com o sistema financeiro e não têm condições de oferecer garantia real e financeira para empréstimos.

Para essas firmas, é necessário desenvolver propostas de investimento, com participação: uma forma mais flexível que permite um aporte de recursos em várias rodadas e não em uma só vez, como se fosse um projeto de investimento em bens tangíveis.

As características das FEBTs são as seguintes:

- Ciclos de vida da tecnologia muito curtos;

- Equação de risco/retorno acima da média;

- Escalas de tempo extremamente curtas para a exploração da tecnologia;

- O investimento na frente em tecnologia pode produzir perdas significativas rapidamente;

- $\mathrm{O}$ acesso ao mercado internacional é frequentemente requerido;

- Pode ser necessário o crescimento rápido das vendas e dos custos associados, para explorar o mercado;

- A saída do investidor frequentemente requer a aquisição ou a ida ao mercado de capitais;

- A assistência gerencial é sempre crítica para o sucesso do empreendimento inovador.

Estes pontos requerem a presença do investidor na firma investida. Neste caso, a regulação da relação credor/devedor feita pelas garantias nos contratos de financiamento via crédito, é inexistente.

Os ativos que são constituídos no processo de crescimento das firmas inovadoras são em sua maioria intangíveis e específicos para uso pela firma. Eles são o resultado do conhecimento tácito e, portanto, de difícil utilização como reserva de valor. A constituição desses ativos demanda longo tempo e os recursos que o compõem são específicos, com uso alternativo limitado. Eles constituem um portfólio em si, integrante do portfólio geral da empresa. Se os outros ativos detidos pela empresa apresentarem expectativas de fluxo de caixa mais favorável e expectativas de resultados menos incertos, o investimento em inovação será restringido ao menor nível possível. Como exemplo, em uma conjuntura em que a aplicação de recursos em títulos públicos apresente altos rendimentos no curto prazo e baixo risco, por que a empresa iria aplicá-los (além do mínimo necessário) em atividades cujo resultado é incerto e de longo prazo de maturação?

Em cenários de maior incerteza, setorial e macroeconômica, os investimentos em inovação serão orientados para atividades que demandem menores gastos e onde os 
resultados sejam alcançados em prazo mais curto, como por exemplo, novos procedimentos de controle de qualidade e racionalização gerencial.

Porém, o montante de recursos para investimento nos ativos centrais pró-inovação, pode ter níveis mínimos em função da natureza setorial da tecnologia, da intensidade da competição e das economias de escala e de escopo que viabilizam o retorno desse investimento no mercado. Nestas condições, as empresas inovadoras estarão condenadas a uma estratégia defensiva e de pouca geração de inovação própria. Vão preferir os contratos de licenciamento de tecnologia que oferecem a vantagem de menor incerteza técnica e econômica, menor gasto e retorno mais rápido. A desvantagem desta estratégia é que ela não oferece alternativa de maior autonomia tecnológica. Nela estão acoplados vários mecanismos que tendem a aprofundar esta trajetória como compra de máquinas e equipamentos, a padronização técnica da produção, e as normas e procedimentos operacionais. Do ponto de vista tecnológico, estes contratos levam o licenciado a dominar a fabricação e a engenharia de detalhe, mas permanece com o licenciador o controle técnico e legal da capacidade de introduzir inovações. Ou seja, a estratégia baseada no licenciamento não leva ao desenvolvimento de um conjunto de ativos de inovação que conduzam para uma estratégia ofensiva de capacitação tecnológica e à melhora da inserção internacional.

Em tais circunstâncias, os mecanismos de mercado são inadequados para induzir o aumento dos investimentos em inovação. A intervenção direta do Estado é necessária para criar um ambiente mais propício e benigno para que as firmas ultrapassem os níveis mínimos de investimento em inovação.

Nas economias em que as empresas são caracterizadas pela constituição de ativos de inovação, baseados em níveis mínimos de investimento, a relação entre as diversas funções do sistema de inovação é muito limitada. Estas interagem pouco entre si e não criam efeitos de encadeamento e de mútuo fortalecimento. A baixa intensidade tecnológica destas interações leva a que as instituições de pesquisa científica e tecnológica também se adequem a esta trajetória de baixa intensidade tecnológica.

Este processo cumulativo negativo atinge desde a formação de recursos humanos para as empresas - que são preparados principalmente para o trabalho em um contexto de baixa intensidade tecnológica - até a inadequada relação entre o sistema financeiro e o produtivo. 


\section{CONCLUSÃO}

No Brasil as FEBTs não são atendidas pelo sistema bancário; pagam os custos mais altos pelos serviços financeiros e estão sujeitas a condições contratuais extorsivas. É necessário abrir um canal institucional para a colocação de títulos de dívida destas empresas, permitindo que estes sejam securitizados de forma coletiva, de diminuir seu risco através de um instrumento, formado pelo Estado, de garantia de liquidez. Se as empresas já estiverem operando em alguma forma de aglomeração produtiva - como os sistemas locais de produção - em que exista alguma forma de cooperação entre elas, a pré-condição de compartilhamento do risco já está dada, bem como a condição para sua securitização coletiva.

O sistema financeiro brasileiro terá que ser preparado para desenvolver um mercado de títulos privados e para desempenhar um papel mais positivo no novo ciclo de investimento que se abre à economia brasileira. Isto exige uma grande redução do espaço ocupado pelos títulos da dívida pública e requer a redução da taxa de juros básica (SELIC), bem como dos seus prazos e condições de vencimento. No Brasil, é tão alto o risco do investimento em qualquer título privado, nas condições em que são oferecidos os títulos da dívida pública, que o cálculo do risco do investimento em inovação - ativo de alto risco, longo prazo de maturação e elevado custo - é praticamente impossível de ser assumido por qualquer instituição financeira privada.

Para investimento em títulos desta natureza, as regras de governança corporativa devem ser aperfeiçoadas. Para isso, é necessária a participação do Estado:

- Na regulação e definição dos critérios de contabilização dos ativos intangíveis;

- Na definição das regras de apresentação das demonstrações financeiras para as firmas de capital fechado;

- Na regulação dos conselhos de administração para estas firmas, e;

- No apoio para a formação de um mercado secundário para dar agilidade e segurança na negociação destes títulos.

A incerteza pode ser crucial para a constituição de um mercado de títulos de dívida privada para o investimento em inovação. As empresas que investem em inovação, um ativo de alto grau de incerteza quanto ao resultado, longa duração e alto custo, devem ter condições de operar em um ambiente onde as suas expectativas quanto às receitas de caixa sejam menos incertas. Caso esta incerteza perdure, os mercados para títulos de dívida privada não serão suficientes para garantir o financiamento adequado da expansão dos investimentos em inovação. 
$\mathrm{Na}$ transição para uma macroeconomia mais progressista que fortaleça a formação do mercado privado de títulos, o Estado terá que desempenhar um papel relevante. Pelo menos no início, ele terá que ser o market-maker, particularmente para o mercado de títulos de dívida privada de longo prazo. Para o mercado de títulos de pequenas e médias empresas inovadoras, um segmento do mercado mais geral, são necessárias medidas especiais para a criação de um lastro para os títulos de dívida, pois essas empresas, não têm capacidade para a emissão e colocação de papéis próprios no mercado.

A Finep, empresa pública especializada no financiamento da inovação poderia ter a sua função ampliada, para exercer o papel de securitizar a demanda de crédito dessas empresas. Assim, em primeiro lugar, a Finep absorveria os seus títulos com os recursos dos fundos setoriais. Em segundo lugar, usaria estes recursos como base para um seguro de crédito visando o lançamento de títulos junto aos investidores institucionais, como fundos de pensão ou fundos de investimento. Ela já exerce a função de Secretaria Executiva do Fundo Nacional de Desenvolvimento Científico e Tecnológico-FNDCT, que congrega os 14 fundos setoriais criados a partir de 1999. No acumulado entre 1999 e 2005, pode-se estimar que foram contingenciados cerca de $\mathrm{R} \$ 4$ bilhões, sendo que apenas no Governo Lula o valor total chega a $\mathrm{R} \$ 2,54$ bilhões. A destinação de $40 \%$ desses recursos para o mercado de crédito e títulos de dívida voltados para o financiamento da inovação já seria um grande avanço para a securitização destes papéis - e a base sobre a qual se ergueria o mercado de compra e venda destes títulos.

O investimento em participação nas FEBTS requer uma maior parceria ou cooperação entre o investidor e o investido. O venture capital é uma parte menor deste mercado mais amplo de participações, e provavelmente mais difícil de ser replicada fora das condições em que floresceu nos EUA, como apontam Chesnais e Sauviat (2000). Isso, porém, não impede a busca de formas específicas e compatíveis com o marco histórico e institucional em que se constituíram, no Brasil, as relações entre o sistema financeiro e produtivo. 


\section{REFERÊNCIAS}

CHESNAIS, F.; SAUVIAT, C. (2000) The financing of innovation-related investment in the contemporary global finance-dominated accumulation regime. In: CASSIOLATO, J. E.; LASTRES, H. M. M.; MACIEL, M. L. Systems of innovation and development. Rio de Janeiro: IE/UFRJ, 2003. p. 61-118.

FINANCIADORA DE ESTUDOS E PROJETOS. Disponível em: $<$ http://www.finep.gov.br>.

MELO, L. M de. $\mathbf{O}$ financiamento ao desenvolvimento científico e tecnológico: a experiência da Finep - 1967 a 1988. Dissertação (Mestrado em Economia) - IE/UFRJ, Rio de Janeiro, 1988.

MELO, L. M de. O financiamento da inovação industrial. Tese (Doutorado em Economia) - IE/UFRJ, Rio de Janeiro, 1994.

NATIONAL PATTERNS OF R\&D RESOURCES: 1998. Arlington, Virgínia: National Science Foundation. Disponível em: <http://www.nsf.gov/statistics/nsf99335/>. Acesso em: 26/2/2010.

SCIENCE AND ENGINEERING INDICATORS. Arlington, Virgínia: National Science Foundation. 2002.

ORGANIZATION FOR ECONOMIC CO-OPERATION AND DEVELOPMENT. Industrial policy in OECD countries: annual review. Paris: OECD, 1992.

ORGANIZATION FOR ECONOMIC CO-OPERATION AND DEVELOPMENT. Venture capital and Innovation. Paris: OECD, 1996. 
